\title{
The two cultures of 'biopolitics' Comment in response to Liesen and Walsh
}

\author{
Patrick A. Stewart \\ Department of Political Science \\ 428 Old Main \\ University of Arkansas \\ Fayetteville, AR 72701 \\ pastewar@uark.edu
}

$\mathrm{F}$ irst of all, I would like to say that it is an honor to be invited to respond to Liesen and Walsh's wonderfully incisive essay on the capture and reframing of the term biopolitics. Being among the initial generation of Ph.D. students at Northern Illinois University whose first field was affectionately christened biopolitics-a shorthand for the official field definition of politics and the life sciences-it was quite perturbing to discover there was another group of scholars using the term in a much different way. Moreover, as a member of the Executive Council for the Association for Politics and the Life Sciences (APLS) since 2005, the encroachment of these scholars on my beloved term gave pause for consideration of just where our organization stood in the two decades that had passed since I first became introduced to this term.

In this response, I first posit that the "scientific biopolitics" of APLS and the biopolitics of postmodernists reflect the "two culture" divide between science and literature noted by C. P. Snow in $1959,{ }^{1}$ albeit a divide that is intensified by two attributes of postmodernism: a studied lack of understanding of science evident in their critiques, and an apparent reliance on linguistic verbosity that obscures, rather than communicates, meaning. I next provide further support for arguments by Liesen and Walsh concerning the capture of the term biopolitics by considering trends in academic manuscript titles identified through Google Scholar; while at the same time, I provide evidence that while biopolitics has fallen out of use, evolutionary theory is becoming more relevant. I conclude by revisiting the two cultures

doi: 10.2990/32_1_94 recognized by Snow, characterizing the forces driving them and the need for the scientific culture to refocus and redouble its efforts.

\section{The two cultures of biopolitics}

The first consideration is to assess where these two groups using the term biopolitics, one as a scientific reference point, the other as a literary construct, stand in reference to each other. Precedent for understanding the competing understandings of this contested term can be found in the analysis presented by Snow in his 1959 Rede Lecture, "The Two Cultures and the Scientific Revolution." Although Snow, a scientist known for his literary skills, was well aware of the complexity of both scientific and literary lifestyles, he saw a divide in how thinking people approached understanding the world around them, a divide I posit persists to this day and can be seen in the contestation over the term "biopolitics." Indeed, Snow asserted that:

I believe the intellectual life of the whole of western society is increasingly being split between two polar groups...at one pole we have the literary intellectuals, who incidentally while no one was looking took to referring to themselves as "intellectuals" as though there were no others. Between the two a gulf of mutual incomprehension-sometimes (particularly among the young) hostility and dislike, but most of all lack of understanding (pp. 4-5).

Snow goes on to note that while many scientists do not have the depth of knowledge concerning literature 


\section{Biopolitics forum}

of those within the "literary culture," those on the other side:

... are impoverished too-perhaps more seriously, because they are vainer about it. They still pretend that the traditional culture is the whole of "culture," as though the natural order didn't exist. As though the scientific edifice of the physical world was not, in its intellectual depth, complexity and articulation, the most beautiful and wonderful work of the mind of man. Yet most nonscientists have no conception of that edifice at all (p. 15).

Snow's rather damning critique of "intellectuals" may be read as a dated critique except for the fact that it reverberates and perhaps more strongly describes the literary culture of those who have expropriated the term biopolitics, namely those who engage in postmodernist analysis. The lack of general scientific knowledge exhibited by this group is exemplified in the Sokal hoax, in which renowned physicist Alan Sokal submitted the article "Transgressing the Boundaries: Towards a Transformative Hermeneutics of Quantum Gravity"2 to the preeminent postmodern cultural studies journal Social Text in May 1996 to show the lack of understanding scholars critiquing science had about the science itself. This article, which posited that quantum gravity was a social construction, was published despite its lack of scientific merit, and highlighted a lack of standards within the field of postmodern studies.

This lack of scientific merit has been expertly unearthed by Liesen and Walsh, who point out that the postmodern approach, while engaging in a critical perspective, denies the validity of knowledge. While postmodernist critiques may indeed provide value, especially given the intellectual capacity of its practitioners, these critiques are undercut by their denial of meaning outside of context. By positing that he is capable of "exploring the things unexplainable," as an archeologist of meaning and social history (p. 8), exploring expressions of power from long past "truth regimes," as a genealogist (p. 8), and analyzing the "study of the self's relationship to itself" as an ethicist (p. 8), Michel Foucault, founder of the postmodernist school, asserts expertise while denying its relevance.

A further complication with postmodern observations on scientific advances is that such critiques are built on self-referential literature. For instance, in a recent special issue on "Interspecies" in Social Text, Livingston and Puar argue that "taxonomy is central to biopolitics" and that "biopolitics, as Foucault explains, is the process by which humans become a species (and in fact, specimens) to join all other biological species" (p. 7). ${ }^{3}$ Yet they also state "as historians of science have established, this taxonomy is a historical product, founded upon and through early modern and modern racial, class and gendered politics" (p. 7). ${ }^{3}$ The reliance on social constructions, and concurrently literature solely reflecting this bias-as appears to be the case throughout this special issue-suggests no grounding for the science scrutinized other than the social milieu. In other words, apparently postmodernists see society as influencing science, but do not give much consideration to the production of knowledge through science or any discernible scientific impacts on society outside of social context.

A second problem with postmodern approaches is that, despite the laudable literary cleverness of practitioners, which has provided such sentences as "... an exemplar of a widespread groping in the 1980s western biopolitical and other cultural discourse for ways to narrate difference that are as deeply enmeshed in feminism, anticolonialism, and searches for nonantagonistic and nonorganicist forms of individual and collective life, as by the hyperreal worlds of the late capitalism, neo-imperialism, and the technocratic actualization of masculinist nuclear fantasies" ( $p$. 145 ) in review of a primate textbook, the postmodern approach loses its audience through contortions of language. ${ }^{4}$ As can be seen with sentences such as this, postmodern thinking has produced literary onanistic orgies in which the pleasures of the "self's relationship to itself" are quite evident within groups of like-minded thinkers, but denies the realities of intersubjective intercourse required by communication. In other words, it is apparent that, for postmodernists, language is used not to communicate to a larger audience but to impress peers and to intellectually dominate those audiences who might happen upon their communiques. Here, language can be seen as an authoritarian activity in which intellectual dominance is asserted through wordplay, albeit not through evidence that can be shared.

This stands in direct contrast with the goals of science, which subjects informed hunches to empirical examination and then focuses on effectively communi- 


\section{Stewart}

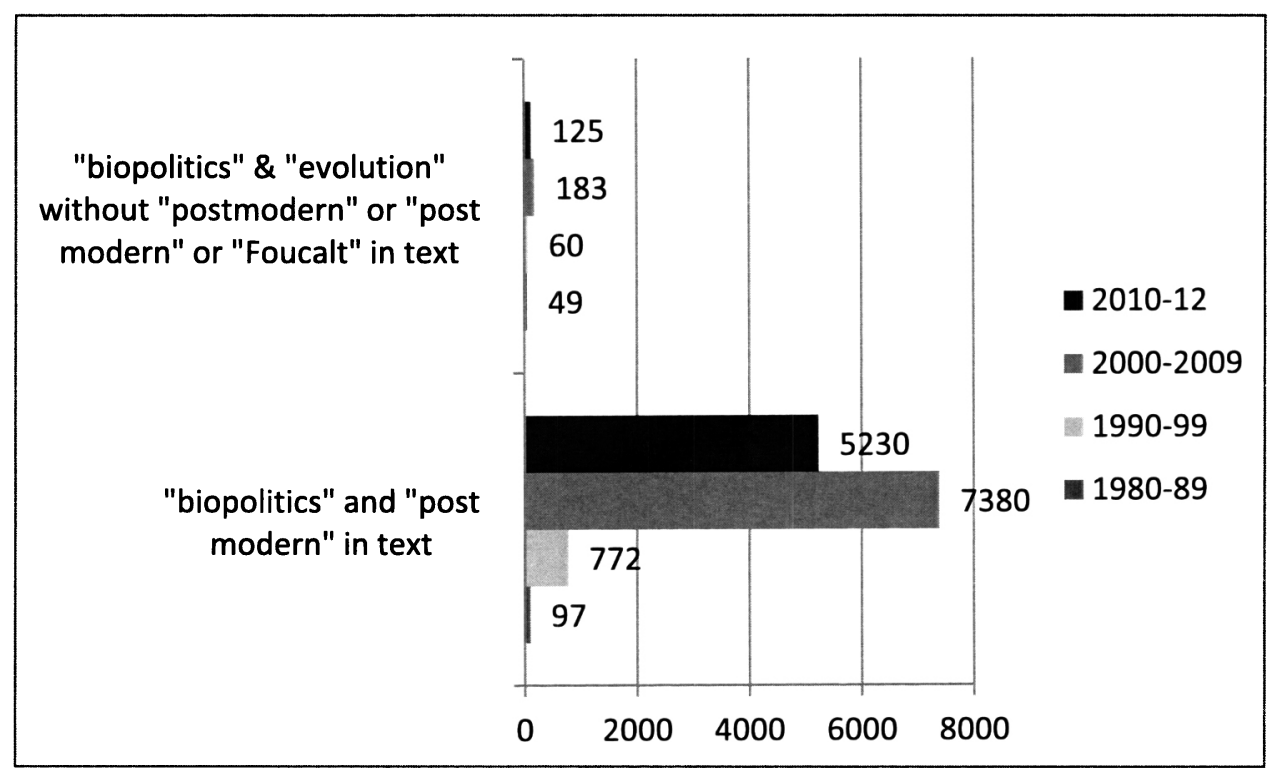

Figure 1. Use of the term "biopolitics" in academic articles, 1980-2012. Source: scholar.google.com (6/26/2012)

cating methods and findings. ${ }^{5}$ As posited by Stuart Firestein, the scientific method consists of an "endless loop of observation, hypothesis, manipulation, further observation, and new hypothesis" (p. 19). ${ }^{5}$ A major goal of the scientific method is to communicate this process of exploration in such as manner as to allow for replication and expansion by other scientists. As such, clear communication becomes a hallmark of good science, and stands in counterpoint to tactics of obfuscation employed by postmodernists.

A second contrast with postmodern approaches is that, while postmodernism focuses on explanation, science cultivates a sense of ignorance, albeit a humble ignorance that stands in contrast to an arrogant ignorance which is marked by an indifference to logic and facts. In the words of Firestein:

But there is another, less pejorative sense of ignorance that describes a particular condition of knowledge: the absence of fact, understanding, insight, or clarity about something. It is not an individual lack of information but a communal gap in knowledge. It is a case where data don't exist, or more commonly, where the existing data don't make sense, don't add up to a coherent explanation, cannot be used to make a prediction or statement about some thing or event. This is knowl- edgeable ignorance, perceptive ignorance, insightful ignorance (p. 7). ${ }^{5}$

Here, the pursuit of knowledge is egalitarian and its possession humbling. It is egalitarian in the sense that, in most circumstances, it ought to be accessible to anyone with a modicum of education. It is humbling in the sense that scientists start with a question-they know they do not know-and ends with even more informed questions: they know more about what they do not know.

\section{Use of the term biopolitics, 1980-2012}

Interestingly, due to the lack of rigor applied by those who use the term biopolitics as a postmodern construct, multiple meanings of biopolitics, which is synonymous with biopower and any other number of other terms-due to it being based upon reader reflection-can be seen. Here, I try to parse its use by the two cultures by carrying out Google Scholar article searches by first searching for the presence of the term "biopolitics" in conjunction with "postmodern" for the literary culture. Searches using the presence of "biopolitics" and "evolution" concurrently with the absence of the terms "post modern/postmodern" and 


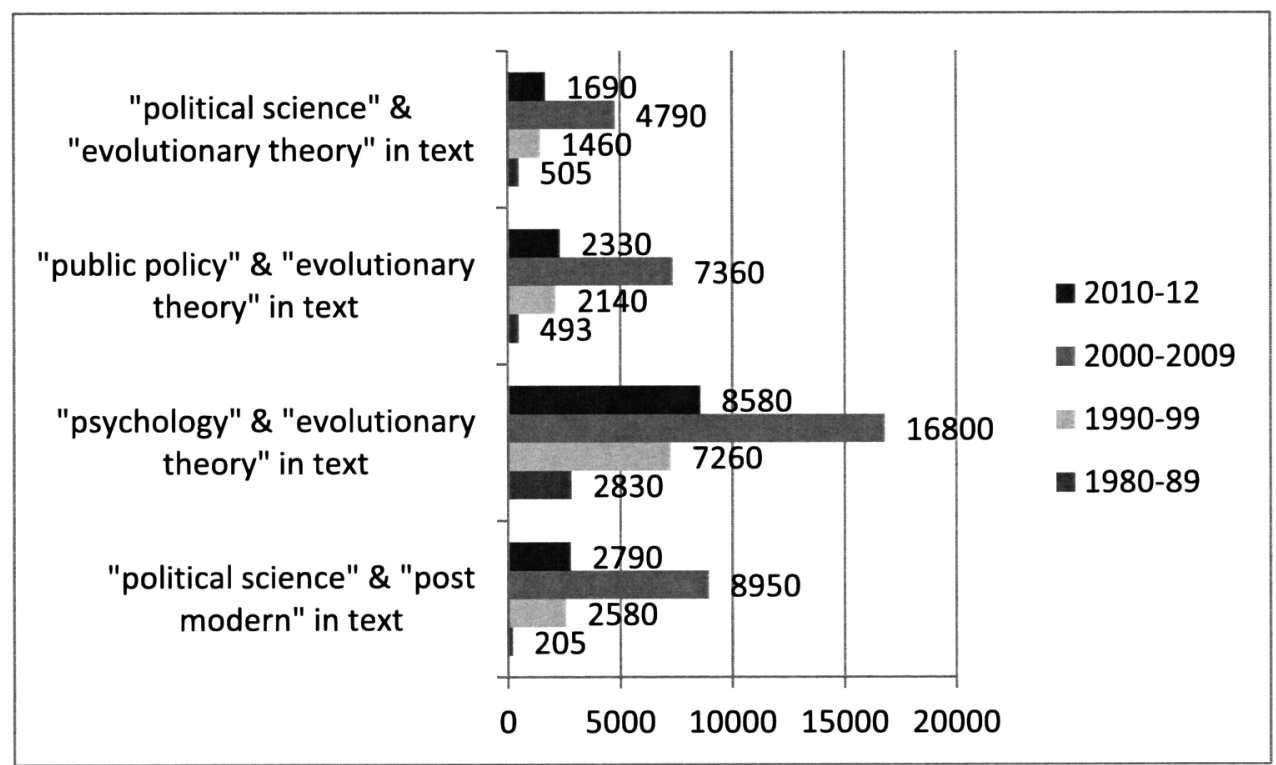

Figure 2. Frequency of the terms "evolutionary theory" and "post modern" by discipline. Source: scholar.google. $\operatorname{com}(6 / 26 / 2012)$

"Foucault" (postmodernism's founder) were carried out to denote the scientific culture. Trends are then considered by searching on a decade basis since 1980 , with results that are both enlightening and, for scientific biopoliticians, disturbing (see Figure 1). Namely, while literary and scientific biopolitics started on an equal footing in the 1980s, there is an order of magnitude difference in the usage of the term by postmodernists from 1990 to the present. The findings here corroborate the observations of Liesen and Walsh.

Interestingly, the appropriation of the term "biopolitics" may be seen as an attempt by postmodernists to retain relevance due to the power of the prefix "bio-" to draw attention to advances in a range of applied fields, most notably in medicine and agriculture, even as the science behind the term is often ignored. This appropriation, however, is not necessarily a bad thing. In the first place, the term biopolitics was mostly used colloquially by its practitioners to refer to a range of life science issues including biobehavior, biopolicy (which was inclusive of a range of biotechnologies), and bioethics. The Association for Politics and the Life Sciences (APLS) functioned as a big top under which all these life science issues were studied. However, these areas are "speciating" with greater precision in how they are approached. Not only are these terms more stringently delineated and delimited as the analysis of them matures, the approaches and topic areas are being increasingly incorporated into the major disciplinary outlets.

An analysis of Google Scholar for trends in the number of times key terms were identified in the text of academic manuscripts shows that postmodernism appears in a large number of publications alongside political science (see Figure 2, bottom row). At the same time, we see a concurrent increase in stated awareness of evolutionary theory in not only political science but also public policy and psychology, suggesting that "biopolitics" may be alive and well, indeed thriving, albeit under a different identity. As discussed by Rebecca Hannagan in this forum, the field of political psychology (along with the larger field of psychology) has increasingly incorporated evolutionary concepts, perspectives, and approaches to address longstanding problems.

Even if the number of individuals using the term biopolitics within critical journals and some political science journals is relatively large (see Figure 1 comparing the presence of the term biopolitics in academic publications), the influence of postmodernists both inside and outside the discipline is likely waning. Within political science, there has been a reduction in the number of political theorists at research universi- 


\section{Stewart}

ties; likewise, in our empirically driven age, it can be expected that this number will continue to diminish throughout the professoriate. Furthermore, the lack of coherence in the use of biopolitics by postmodern theorists and inaccessibility to the public at large suggests that the term's influence will continue to wane for all but an elite who can afford adventures in wordplay. However, as suggested by Amy Fletcher in this forum, literary biopolitics has an important role to play, if literary scholars are up to the challenge of grappling with the science they seek to critique.

Finally, while evolutionary theory may be seen as antithetical to the beliefs of many Americans, popular coverage of evolution has grown, especially as it relates to understanding human behavior. ${ }^{6,7}$ So, while biopolitics may have been invaded in the scholarly realm by postmodern approaches, popular coverage of the fruits of scientific biopolitics has grown extensively, with due regard given to how evolution influences political behavior. Indeed, scientific biopolitics has won-albeit under a different label. While ceding the term biopolitics to postmodernists may be seen as unacceptable to some, understanding that the continued acceptance of evolutionary approaches within social science generally, and political science specifically, has led to the gradual ongoing incorporation of once marginal views within "normal science" 8 should provide some intellectual succor. Indeed, scientific biopoliticians who have fought the good fight for over the 30 years that the Association for Politics and the Life Sciences has been in existence should celebrate the fact that in losing the battle over the word biopolitics they appear to be winning the war for scientific ascendance.

\section{References}

1. Charles P. Snow, "The two cultures," Leonardo, 1990, 23(2/3): 169-173.

2. Alan D. Sokal, "Transgressing the boundaries: Toward a transformative hermeneutics of quantum gravity," Social Text, 1996, 46/47: 217-252.

3. Julie Livingston, Puar, Jasbir K. "Interspecies," Social Text, 2011, 29(1 106): 3-14.

4. Robin I. M. D. Dunbar, The Trouble with Science (Cambridge, MA: Harvard University Press, 1995).

5. Stuart Firestein, Ignorance: How It Drives Science (New York: Oxford University Press, 2012).

6. Allan Mazur, "Believers and disbelievers in evolution," Politics and the Life Sciences, 2004, 23(2): 55-61.

7. Maryanne L. Fisher, Daniel J. Kruger, and Justin R. Garcia, "Understanding and enhancing the role of the mass media in evolutionary psychology education," Evolution: Education and Outreach, 2011, 4(1): 75-82.

8. Thomas S. Kuhn, The Structure of Scientific Revolutions (Chicago: University of Chicago Press, 1996). 